\title{
Chemiresistors based on ultrathin gold nanowires for sensing halides, pyridine and
}

\section{dopamine}

Irina S. Muratova ${ }^{a}$, Konstantin N. Mikhelson ${ }^{a^{*}}$, Yuri E. Ermolenko ${ }^{a}$, Andreas Offenhäusser ${ }^{b}$ and Yulia Mourzina ${ }^{b *}$

${ }^{a}$ Chemistry Institute c/o St.Petersburg State University, Russia

konst@km3241.spb.edu

${ }^{b}$ Forschungszentrum Jülich GmbH and Jülich Aachen Research Alliance (JARA)-Fundamentals of Future Information Technology, Jülich, Germany, y.mourzina@fz-juelich.de

Abstract

Two distinctively different approaches to the deposition of the ultrathin gold nanowires (NWs) on chips for the development of the chemiresistor sensors are studied. The first approach is the deposition of the pre-synthesized NWs on a chip using a microfluidic technique, and the second is the direct synthesis of the NWs on chips. It is shown that the $2^{\text {nd }}$ approach ensures a better contact between the NWs and electrodes, lower resistance of the NW sensor device, and a longer life time of the devices. The current-voltage dependencies obtained for the chips with the NWs in contact with air, and aqueous solutions of $\mathrm{NaF}, \mathrm{NaCl}, \mathrm{NaBr}, \mathrm{NaI}$, pyridine, and dopamine indicate significant changes of the NWs resistance caused by sorption of halides, pyridine and dopamine on the NWs surface. This change of the NWs resistance can be used for quantification of $\mathrm{Cl}^{-}$over a concentration range of $10^{-5}-10^{-3} \mathrm{M}$ and dopamine over a concentration range of $10^{-8}-10^{-5} \mathrm{M}$. Tentatively, it is concluded that the data obtained can be explained in terms of the Langmuir adsorption isotherm.

Keywords: chemiresistor, ultrathin gold nanowires, nanowires deposition, sensing halides, pyridine, dopamine.

\section{Introduction}

Various types of electrochemical sensors are routinely used in clinical, industrial and agricultural applications, in environmental monitoring, and in academic studies [1,2]. A relatively new and fast developing type of electrochemical sensor is represented by chemiresistors or conductancebased sensors. These sensors are capable of changing their resistance in response to the change 
of the chemical composition of the sample [3-5]. This type of sensor relies on electronic effects at the interface, where adsorbate influences the conductivity of the surface layer of the sensing element of the chemiresistor by affecting the number of conduction electrons (electron density), $\Delta \mathrm{n}$, as a result of the formation of local hybridized orbital with the metallic electronic states. Additionally, adsorbate molecules alter the relaxation time of electrons, $\tau$, by acting as scattering centers for conduction electrons. Either effect change the conductivity near the surface [6, 7]. For a film of thickness $t>l_{B}\left(l_{B}\right.$ is the electron mean free path), the ratio of $\Delta \rho$ the adsorbate-induced change in the resistivity over $\rho_{B}$ the bulk resistivity of the film can be written as [6]:

$$
\frac{\Delta \rho}{\rho_{B}}=\frac{l_{B}}{t}\left(\frac{\Delta n}{n_{B}}+\frac{\Delta \tau}{\tau_{B}}\right)
$$

Here the subscript $B$ refers to bulk values. The adsorbate effects on electronic conduction in metals were first described by Fuchs and Wills [8], and then by Sondheimer for the metal thin films [9], and a more complete model was developed in the 1990-s by Persson [6, 10, 11]. According to this model, the increase of the adsorbate density of states at the Fermi energy level of a metal leads to an increase in the resistance of the metal surface, thus predicting the tendency of strongly specifically adsorbed species, e.g., chemisorbed thiols on gold, to give larger effects than that of the weakly adsorbed, physisorbed, species. These effects are especially important for nanowires because of the enlarged surface-to-volume ratio. Respectively, adsorption of various species at the nanowire surface alters their resistivity, and this makes the basis of the resistometric sensing. The small size of chemiresistors, together with label-free, direct and fast sensing procedure make these sensors rather promising. Advances in the field of resistometric sensors have been recently reviewed [12].

The sensing elements in chemiresistors are based on various nano-structurized materials: metal and non-metal nanoparticles [12-17], graphenes and other ultra-thin films [18-21], and carbon nanotubes or those based on conducting polymers [22-27]. Chemiresistors can be successfully used to control $\mathrm{CO}_{2}$ [28], $\mathrm{NO}_{2}$ [21], ammonia [23, 24], and various volatile organic compounds $[23,29,30]$ in air. These sensors are also suitable for water analysis for alcohols [16], sugars [31] and hydrocarbons [16, 32]. One dimensional nanostructures like nanowires (NWs) and nanotubes (NTs) are increasingly used in chemiresistors [33-41], in particular for $\mathrm{H}_{2}, \mathrm{NH}_{3}$, and $\mathrm{NO}_{2}$ gas detection [5], and in biosensing [44, 45].

In this work, we describe chemiresistors based on ultrathin gold nanowires. The approach utilized is based on earlier results [5, 39], where the effect of surface chemistry on electrical 
properties of ultrathin $\mathrm{Au}$ NWs was explored and their functionality as chemiresistors in electrolyte solutions was thus shown. The results were further supported by theoretical considerations [46]. Furthermore, it was shown using chemisorbed alkane thiols with carboxy-, amino-, and methyl- functional groups that interfacial charge enhances the surface-sensitive resistance of the NWs [39]. Applicability of such sensors for studying interfacial properties using electrodes of comparable size to the electrical double layer was thus established. Thiols are specifically adsorbed (chemisorbed) on the gold surface, with gold thiol bonding being very strong with a bond energy of about $160-200 \mathrm{~kJ} \mathrm{~mol}^{-1}$ [47], where charge transfer producing $\mathrm{Au}^{(+)}$ and $\mathrm{S}^{(-)}$(formation of $\mathrm{Au}(\mathrm{I})$-thiolate) is hypothesized [47, 48]. Here we show that ultrathin $\mathrm{Au}$ NWs can be used as chemiresistors for sensing molecules with lower energy of adsorption (not chemisorbed), which was theoretically discussed recently [46] but not explored. Furthermore, we focus here on the techniques aimed at assembling gold NWs on sensor chips, and on the study of these devices as chemiresistors in samples containing halides, pyridine, and dopamine. We also show that for the rationalization of the chemiresistor sensor signal the Langmuir adsorbtion isotherm may be used. To the best of our knowledge, the aforementioned analytes so far have not been quantified using chemiresistors based on ultrathin gold nanowires.

\section{Experimental}

\subsection{Chemicals and materials}

The chemicals for the synthesis of gold nanowires: $\mathrm{HAuCl}_{4} 3 \mathrm{H}_{2} \mathrm{O}(99.9 \%)$, toluene, hexane, acetone, oleylamine (OA) (technical grade, 70\%), ascorbic acid (AA), absolute ethanol, isopropanol, and those used for the electrochemical measurements: $\mathrm{NaF}, \mathrm{NaCl}, \mathrm{NaBr}, \mathrm{NaI}$, phosphate buffer components, pyridine, dopamine (DA) were of analytical grade (SigmaAldrich). Poly(methyl methacrylate - methacrylate) 33\% (PMMA-MA 33\%), PMMA 50 K, PMMA 600K, PMMA developer AR 600-55 K were from ALLRESIST GmbH, Germany. All aqueous solutions were prepared with deionized (DI) water with the resistivity of $18.2 \mathrm{M} \Omega$, Milli-Q Reference Water Purification System, France.

\subsection{Apparatus}

Electrical measurements were performed with Keithly semiconductor analyzer (model 4200 SCS). UV-Vis spectra were recorded with spectrometer Lambda 900, PerkinElmer. The thickness of the resists layers were measured with ellipsometer Sentech SE800. Oxygen plasma 
treatment was performed in a plasma oven (Diener electronic $\mathrm{GmbH}$ ). Scanning electron microscopy (SEM) was carried out on a Zeiss Gemini 1550 device.

\subsection{Device fabrication}

Sensor chips as substrates for the deposition of nanowires were prepared using an e-beam lithography (EBL) in ISO2 clean room. A sensor chip contained the pairs of electrodes designed to contact the Au NWs (referred to as contact electrodes) with a spacing of 400, 600, $800 \mathrm{~nm}$, or $1 \mu \mathrm{m}$ (altogether 30 electrode pairs), contact lines, and bond pads. The chip overview is shown in Fig. 1.

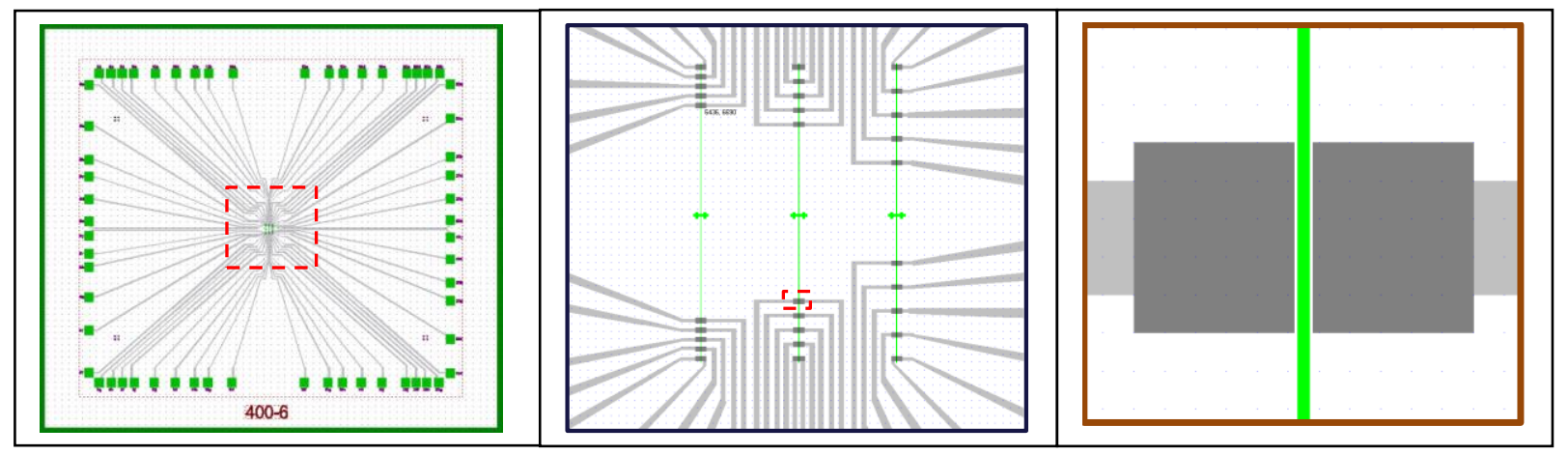

Fig. 1. The chip overview (left), the chip central part with the pairs of contact electrodes (middle) and a pair of contact electrodes (right). Green lines show the channel in the PMMA insulation layer, which was opened after the chip insulation and where the NWs were in contact with an electrolyte solution.

A silicon substrate was coated with a $1 \mu \mathrm{m}$ silicon oxide layer prepared by wet oxidation. A layer of poly(methyl methacrylate - methacrylate) 33\% (PMMA-MA 33\%), used as an electron beam resist, was spun at $2000 \mathrm{rpm}$ over the substrate. The thickness of the resist (proved ellipsometrically) was $200 \mathrm{~nm}$. The spin-coated electron beam resist was then pre-baked for 10 min. Afterwards, PMMA $50 \mathrm{~K}$ was spun at $2000 \mathrm{rpm}$ over the resist surface. The thickness of this new PMMA layer was of $40 \mathrm{~nm}$ and the sample was pre-baked again for $5 \mathrm{~min}$. After that, the lanes to deposit the metal leads (contact lines) and the contact pads were patterned using EBL by applying a dose of $200 \mu \mathrm{C} / \mathrm{cm}^{2}$. The development of the electron beam resist was carried out for 2 min. using the PMMA developer AR 600-55 K. The process was terminated by immersion into isopropanol for $30 \mathrm{~s}$. After that, the pieces were dried in nitrogen flow. Afterwards, $10 \mathrm{~nm}$ layer of titanium and $50 \mathrm{~nm}$ layer of gold were deposited over the substrate 
by electron beam evaporation. The gold contact electrodes, leads and contact pads were formed by means of lift-off process.

\subsection{Synthesis of gold NWs}

The Au nanostructures were synthesized following slight modifications to the procedure [49, 50]. According to this method, ultrafine gold nanoparticles of about $2 \mathrm{~nm}$ are attached to each other (with a very narrow size distribution) either in the solution phase and then deposited on a substrate, or the NWs are directly attached to a substrate. Both processes are facilitated by a selective removal of the capping agent from specific crystallographic facets. This allows for the formation of long ultrafine nanowires of uniform diameter by oriented attachment mechanism. For the synthesis of gold NWs, $4 \mathrm{mg}$ of $\mathrm{HAuCl}_{4} \cdot 3 \mathrm{H}_{2} \mathrm{O}$ was added to $10 \mathrm{ml}$ of toluene. Next, 80 $\mu \mathrm{l}$ of oleylamine $(\mathrm{OA})$ as a reducing and stabilizing agent was added to this mixture and sonicated for 10-15 seconds. The mixture turned bright yellow indicating that the gold salt gets dissolved forming $\mathrm{Au}(\mathrm{III})$-amine complex. After that, the solution was heated from room temperature to about $100{ }^{\circ} \mathrm{C}$, and then kept at this temperature for 30-35 min, until the color of the solution became pale pink indicating the appearance of small gold nanoparticles. Next, the solution was cooled down to $40{ }^{\circ} \mathrm{C}$ over a period of 5-7 min. After that, $16 \mathrm{mg}$ of ascorbic acid was added to the solution. This invoked the grouping of small gold NPs into NWs by the oriented attachment mechanism $[39,51]$. The solution was kept at $40{ }^{0} \mathrm{C}$ for 3 hours with mild shaking. During this time, the solution turned from pale pink to dark violet. The solution was then left to cool down to room temperature. UV-Vis spectra (see Fig. 2) confirm the presence of NWs in the solution. The peak at $550 \mathrm{~nm}$ refers to gold nanoparticles, and a broad peak at about $1300 \mathrm{~nm}$ refers to the high aspect ratio gold NWs in the solution [52]. Formation of NWs can be seen also with a naked eye: dark violet color shown in Fig. 2, inset, indicates the presence of NWs in the solution. The diameter of the NWs obtained was 2-5 nm as shown in the AFM and SEM images, see Fig. 3. 


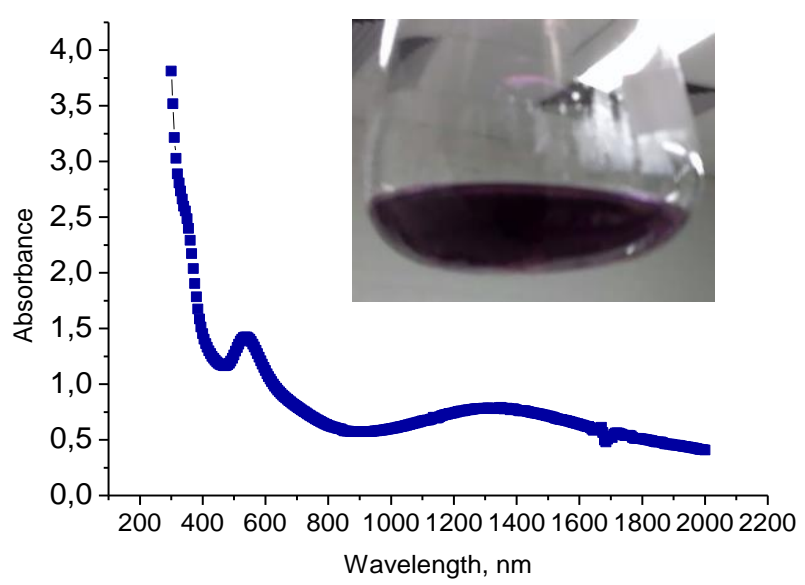

Fig.2. UV-Vis absorption spectrum of the solution with gold nanostructures after the synthesis, the inset shows a flask with dark violet solution containing gold NWs.
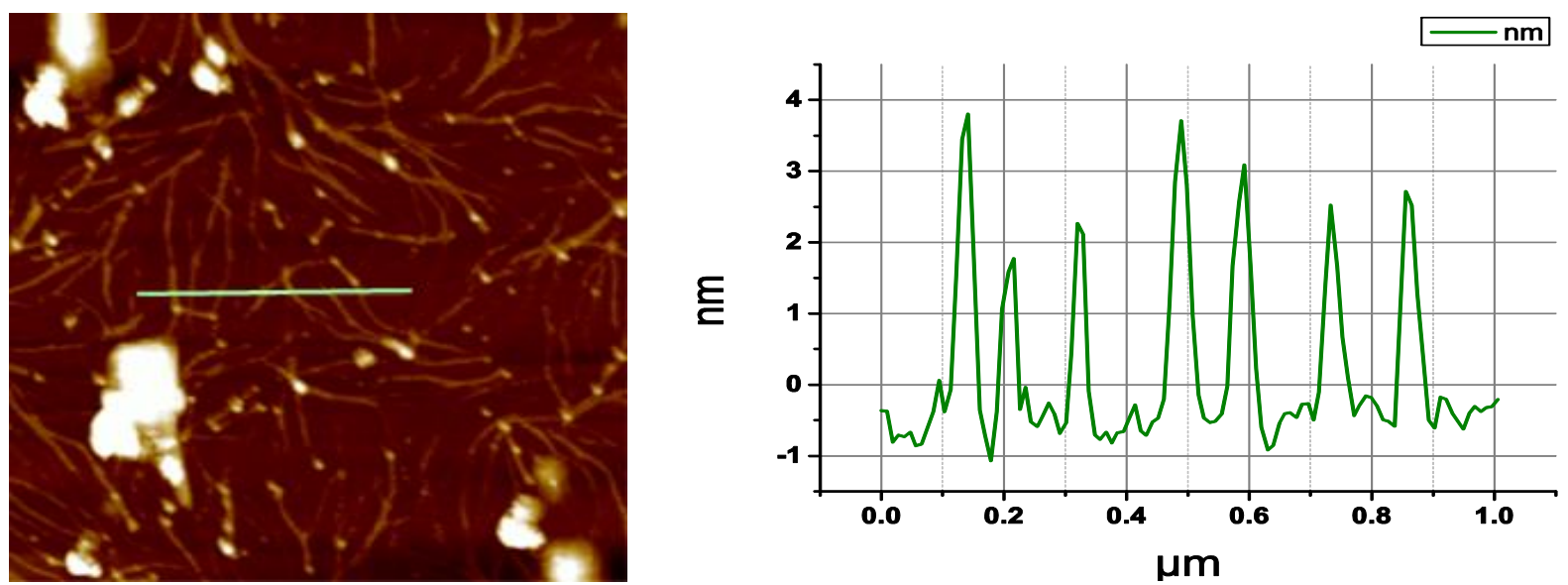

Fig. 3. AFM image of gold $\mathrm{NWs}$ on $\mathrm{Si} / \mathrm{SiO}_{2}$ substrate.

\subsection{Electrical characterization}

The electrical characterization of the nanowires was carried out by employing a Keithly semiconductor analyzer. The NWs were electrically contacted through the bond pads using tungsten needles. The electrical characterization was based on a two-point probe measurement, where DC voltages were applied and the resulting current was measured. The resistance of the nanowires was then calculated from the current-voltage (I-V) curves. Initially, we used the voltages up to $\pm 1 \mathrm{~V}$, but due to their fragile nature, the NWs were damaged by these voltages. Therefore, most the data were obtained using the potential ranges from -0.1 to +0.1 or -0.2 to $+0.2 \mathrm{~V}$.

The preliminary I-V measurements were performed before the insulation of the electrodes with PMMA. This was done to reject chips with a poor contact between the NWs and the electrodes. 
After insulation, I-V characterization of each device, containing the nanowires, was performed in air and in contact with aqueous solutions. The experiments with solutions were done using a drop of $20 \mu \mathrm{l}$ of the respective solution, which was placed in the center of the chip. After each measurement the devices were thoroughly rinsed with Milli-Q water.

\section{Results and discussion}

\subsection{Optimization of the deposition of the gold nanowires on chips: direct synthesis vs.} microfluidic approach

To deposit the NWs on chips with pre-structured electrode pairs and contact lines (as described in section 2.3), we have explored two techniques: (i) deposition of the pre-synthesized NWs on electrodes using a microfluidic channel, and (ii) a direct synthesis technique when the NWs were synthesized directly on the electrodes.

In general, the microfluidic technique is more suitable for regular orientation of the deposited NWs, which are directed and oriented by the direction of the solution flow. This technique must ensure high spatial resolution and possibility to select the position of the NWs on the chip, it also allows for a better control of the number of the NWs deposited on the chip. We utilized two microfluidic channels (both made of PDMS): with widths of 100 and 500 microns, see Fig. S1 (Supporting Information). The channels were cleaned with oxygen plasma for $5 \mathrm{~min}$ and then positioned upside down on chips to deposit the NWs. The NWs solution was passed through the channel by either a syringe pump with a flow rate of 100 or $200 \mu 1 / \mathrm{min}$, or by a peristaltic pump with a flow rate of $60,100,409,550 \mu \mathrm{l} / \mathrm{min}$, using either toluene or hexane as solvent.

The best results have been achieved with the channel of 500 microns width, using a peristaltic pump at flow rate of $100 \mu \mathrm{l} / \mathrm{min}$. Unfortunately, according to SEM images (Fig S2 in Supporting Information), the NWs were often deposited non-uniformly: mostly in the middle and at the end of the channel, with almost no NWs in the beginning, and randomly orientated, regardless of whether toluene or hexane was used as a solvent. Furthermore, the electric currents in the devices prepared by the microfluidic technique were rather low $\left(10^{-12}-10^{-9} \mathrm{~A}\right)$, suggesting that only part of the NWs deposited on the chip by the microfluidic channel technique contacted the electrodes, Fig S2 (Supporting Information). This is consistent with literature data [53]. Also, these NWs were rather unstable over time, and the output of the working devices was low.

In method 2, to synthesize the NWs directly on the pre-structured chips with electrode pairs and contact lines; the latter were placed into the flask before the synthesis of the NWs (see section 2.4), and were taken out from the solution with tweezers after the synthesis. The chips were 
cleaned by dipping into ethanol, deionized water and acetone for 2 minutes each, and after that dried in air. The direct synthesis of the NWs on the chip did not ensure high spatial resolution: the NWs grow over the entire chip surface including the contact lines, contact pads and contact electrodes themselves. However, this technique ensured good contact between the NWs and the electrodes, also the adhesion of the NWs to the chip surface was better and the NWs deposited in this way were stable over 15-20 days. The SEM images of the gold NWs directly synthesized on the chip surface are shown in Fig. 4 and Figs. S3-S6 (Supporting Information). The electric current in these devices was of $10^{-9}-10^{-6} \mathrm{~A}$, thus in one to three orders of magnitude higher than in devices made by the microfluidic technique.

The fact that the NWs are present not only in between the electrodes is of minor importance because after the deposition of the NWs the whole chip surface was insulated with PMMA $600 \mathrm{~K}$, applied as a solution in ethyl lactate. The insulation layer thickness was about $220 \mathrm{~nm}$. Due to the thermal instability and melting of nanowires at high temperatures, ethyl lactate was left to evaporate slowly and under mild conditions during the preparation of the insulation layer: for $36 \mathrm{~h}$, at room temperature. The areas of the contact pads and those between the electrode pairs containing the nanowires were patterned by EBL using a dose of $180 \mu \mathrm{C} / \mathrm{cm}^{2}$. The development and the removal of PMMA from these patterned areas were performed as described in section 2.3, and in this way the channels (marked as green lines in Figure 1) were generated between the electrode pairs, leaving the NWs exposed to the environment. The geometric area of the opened (non-insulated) surface of the chip was ca $1 \cdot 10^{-6} \mathrm{~cm}^{2}$.

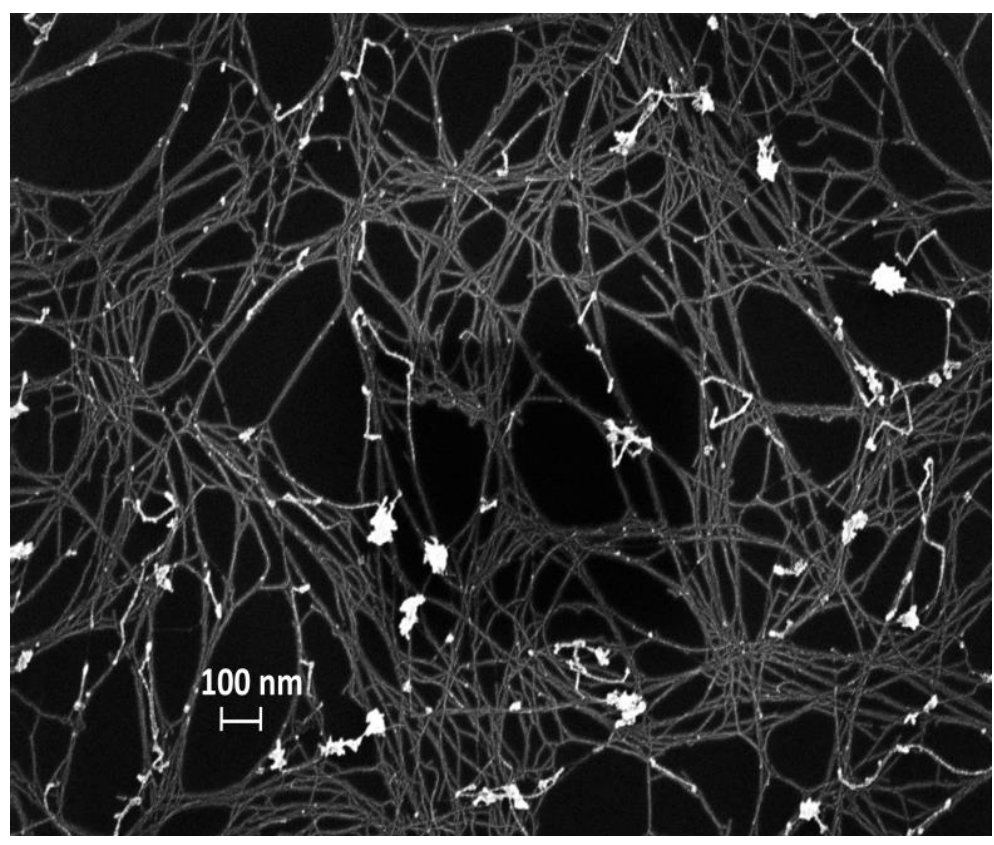

Fig. 4. SEM image of the gold NWs directly synthesized on the chip surface. 


\subsection{The chemiresistor sensor response to halides and pyridine}

Based on the literature data $[54,55]$, we have chosen sodium halides $(\mathrm{NaF}, \mathrm{NaCl}, \mathrm{NaBr}, \mathrm{NaI})$ as adsorbates to study the behavior of the chips as chemiresistors. Another object of the studies was pyridine. Pyridine features two distinctive molecular sites: an aromatic ring and a lone electron pair on the nitrogen atom which can coordinate surfaces of metals. This makes pyridine an ideal molecule for the studies of adsorption on metals [56-58].

The concentration of these solutions varied within the range from $10^{-5}$ to $10^{-3} \mathrm{M}$. In these experiments, the distance between the contact electrodes in each electrode pair was $600 \mathrm{~nm}$. In turn, the distances between the adjacent electrode pairs in the chips were 5, 10 or $20 \mu \mathrm{m}$. The volume of the solution drops casted on top of the chips for measurements was $20 \mu 1$.

The individual resistance values of the individual pairs of the contact electrodes crossed by the NWs vary, however the regularities of the resistance obtained with 10 individual electrode pairs were the same. The increase of the distance between the adjacent electrode pairs from 5 to 10 to $20 \mu \mathrm{m}$ did not cause any regular change of the resistance, however the scattering of the data was the lowest for the electrode pairs with $5 \mu \mathrm{m}$ distance between the adjacent pairs. Respectively, these results were the closest to the average values.

The results obtained with $\mathrm{NaF}, \mathrm{NaCl}$, and $\mathrm{NaBr}$ solutions are presented in Figs. 5, 6. The current responses to the applied voltage are linear, indicating the Ohmic behavior of the gold NWs. The conductance of the wires in contact with $1 \mathrm{mM} \mathrm{NaF}$ is smaller than in contact with the ambient air, but much larger than in contact with $\mathrm{NaCl}$ or $\mathrm{NaBr}$ solutions. These results are consistent with the known fact that fluoride adsorption on gold is much weaker than that of other halides, and follows the order: $\mathrm{F}^{-}<\mathrm{Cl}^{-}<\mathrm{Br}^{-}<\mathrm{I}^{-}[54,55]$.

Unlike $\mathrm{NaF}$, even much smaller concentrations of $\mathrm{NaCl}$ and $\mathrm{NaBr}$, starting from $10^{-5} \mathrm{M}$ caused significant decrease of the current/voltage slope, i.e. the resistivity of the NWs increased in the presence of $\mathrm{Cl}^{-}$and $\mathrm{Br}^{-}$. The effect intensifies with the increase of $\mathrm{Cl}^{-}$and $\mathrm{Br}^{-}$concentration (see Figs. 5, 6). This allowed us to use $1 \mathrm{mM} \mathrm{NaF}$ as a background electrolyte in further measurements with halides.

NWs as chemiresistors can be characterized in terms of the relative change of the resistance: the difference between the resistances in a sample and in a reference solution, divided by the resistance measured in the reference solution $[3,4,8,10,40]$ : 
$\Delta R / R=\left(R_{\text {Sample }}-R_{\text {Ref }}\right) / R_{\text {Ref }}$

Here $R_{\text {Sample }}$ is the NWs resistance registered in contact with a sample solution, e.g. $\mathrm{NaCl}$, and $R_{\text {Ref }}$ is the NWs resistance in contact with $1 \mathrm{mM} \mathrm{NaF}$ which we have chosen as the reference solution. Division by $R_{\text {Ref }}$ allows for a partial compensation of the individual properties of the particular NWs arrays in chips. The mean values of $\Delta R / R$ and the respective standard deviations are shown in insets in Figs. 5, 6. It can be seen that $\Delta R / R$ increases from about 0.3 for $10^{-5} \mathrm{M}$ $\mathrm{NaCl}$ to 0.8 for $10^{-3} \mathrm{NaCl}$, whereas in the case of $\mathrm{NaBr}$ the respective change is from 3.3 to 4.2. Thus, $\Delta R / R$ the relative change of the resistance in the case of $\mathrm{NaBr}$ is larger than that for $\mathrm{NaCl}$, however the increase of this value along the increase of the electrolyte concentration in the case of $\mathrm{NaBr}$ is lower. Apparently, due to a stronger adsorption of $\mathrm{Br}^{-}$, the coverage of the gold surface with $\mathrm{Br}^{-}$is more complete even at lower concentration of $\mathrm{Br}^{-}$anion in the solution. This is why the $\Delta R / R$, per se, for $\mathrm{NaBr}$ is higher than for $\mathrm{NaCl}$, but its increase along the concentration of the electrolyte is lower.

Iodide, apparently, is adsorbed even stronger: the data obtained suggest higher resistivity than in the presence of $\mathrm{Cl}^{-}$and $\mathrm{Br}^{-}$, see Fig. S7 (Supporting Information). Furthermore, the curves recorded for $10^{-5}, 10^{-4}$ and $10^{-3} \mathrm{M} \mathrm{NaI}$ practically coincide. This may indicate that already $10^{-5}$ $\mathrm{M} \mathrm{NaI}$ is enough for a full coverage of the surface of the NWs. On the other hand, very low current (about $10^{-10} \mathrm{~A}$ ) and poor response of the chips after measurements in NaI imply gradual destruction of the NWs in contact with iodide solutions. SEM images see Fig. S8 (Supporting Information) confirm a partial destruction of the NWs after contact with NaI. 


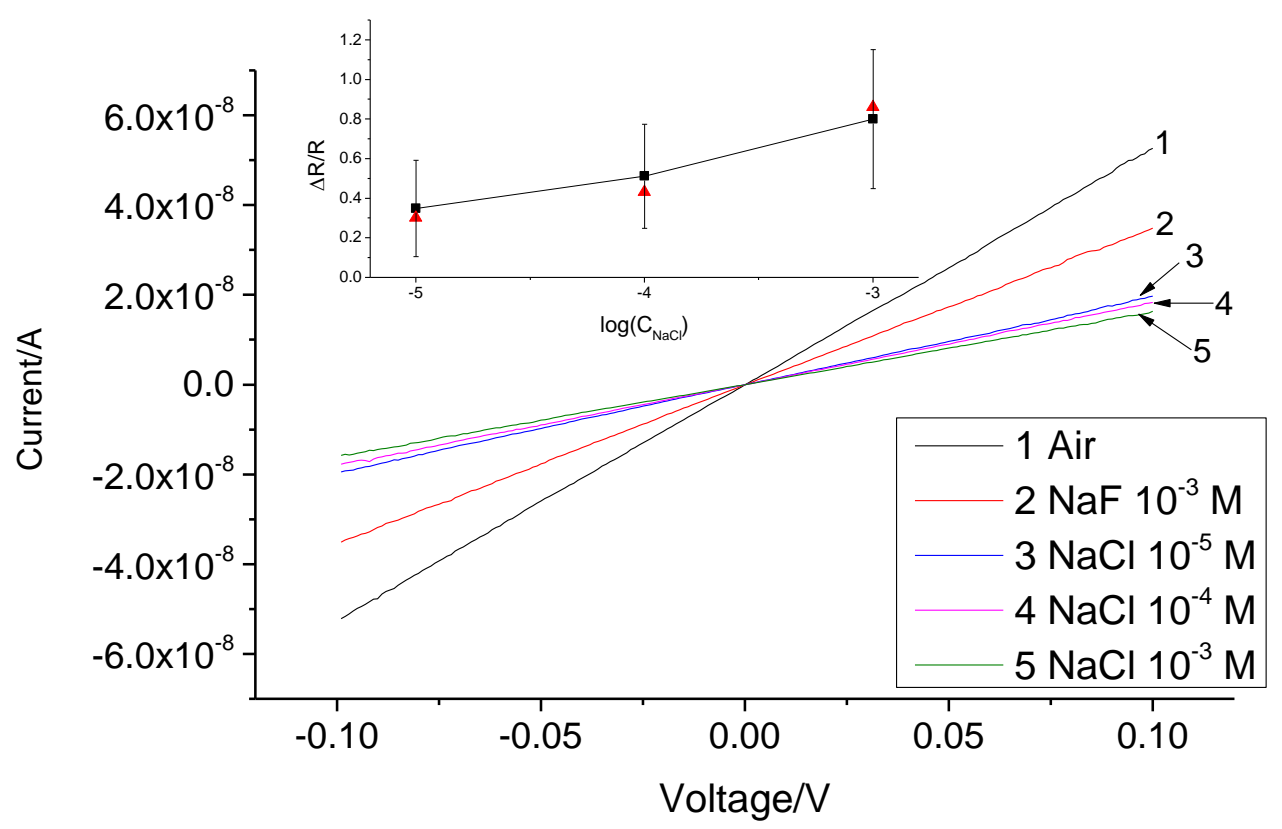

Fig. 5. Current-voltage dependences obtained for a chemiresistor chip with $600 \mathrm{~nm}$ distance between the contact electrodes and $5 \mu \mathrm{m}$ distances from the adjacent contact electrode pairs. The data refer to the electrodes in contact with the ambient air, with $1 \mathrm{mM} \mathrm{NaF}$, and with $\mathrm{NaCl}$ solutions. The inset shows the $\Delta R / R$ values vs. logarithm of the $\mathrm{NaCl}$ concentration (average data for the whole chip). Triangles in the inset refer to current-voltage dependences shown in the main figure.

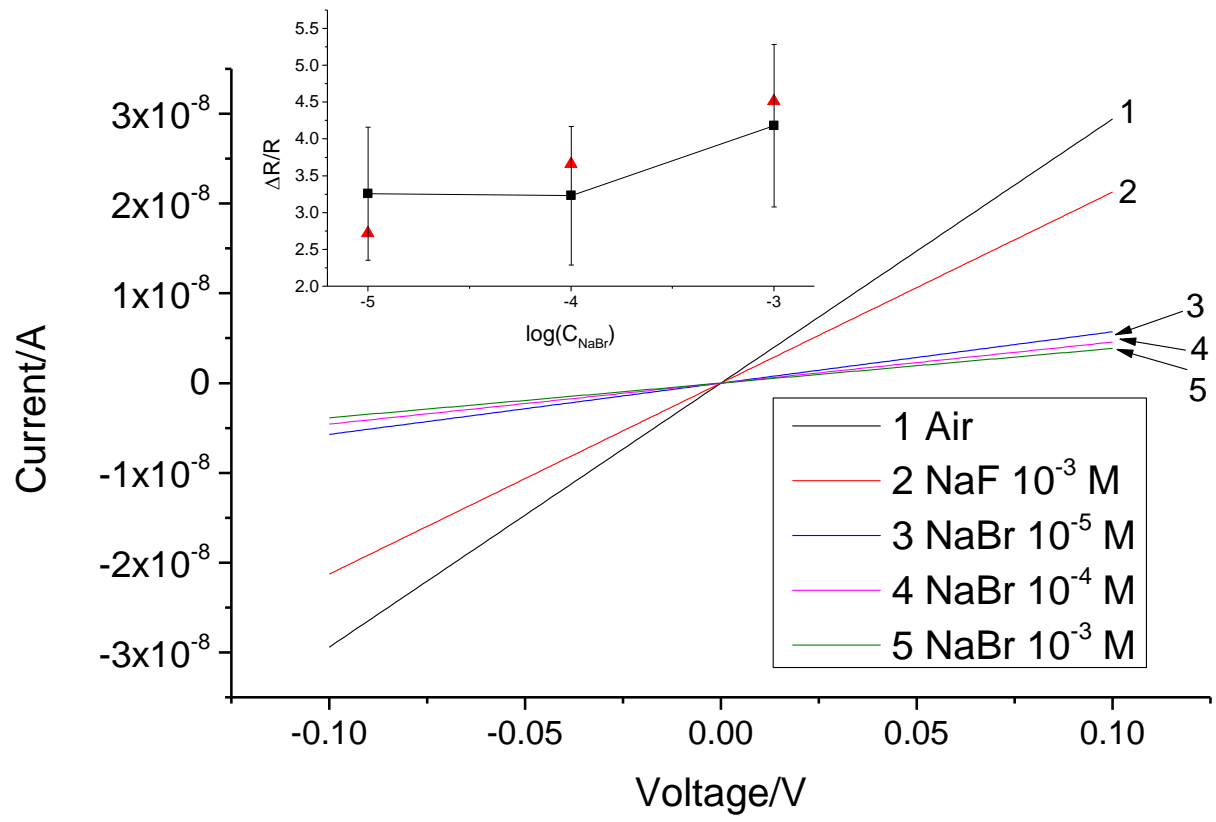

Fig. 6. Current-voltage dependences obtained for a chemiresistor chip with $600 \mathrm{~nm}$ distance between the contact electrodes and $5 \mu \mathrm{m}$ distances from the adjacent contact electrode pairs. The data refer to the electrodes in contact with the ambient air, with $1 \mathrm{mM} \mathrm{NaF}$, and with $\mathrm{NaBr}$ 
solutions. The inset shows the $\Delta R / R$ values vs. logarithm of the $\mathrm{NaBr}$ concentration (average data for the whole chip). Triangles in the inset refer to current-voltage dependences shown in the main figure.

Typical results obtained for the chips with a distance of $600 \mathrm{~nm}$ between the electrodes in aqueous pyridine solutions, over the concentration range from $10^{-5}$ to $10^{-3} \mathrm{M}$, with $10^{-3} \mathrm{M} \mathrm{NaF}$ as background electrolyte are shown in Fig 7. One can see that the slope of the I-V curves is regularly decreasing with the increase of the pyridine concentration, like in the case of chloride and bromide. The relative change of the resistance when $\mathrm{NaF}$ is replaced with pyridine is large: approx. 4 times, but the change of this value with the increase of the pyridine concentration does not exceed the measurement error. Apparently, already in contact with $10^{-5} \mathrm{M}$ pyridine solution gold NWs surfaces are largely covered with adsorbed pyridine molecules.

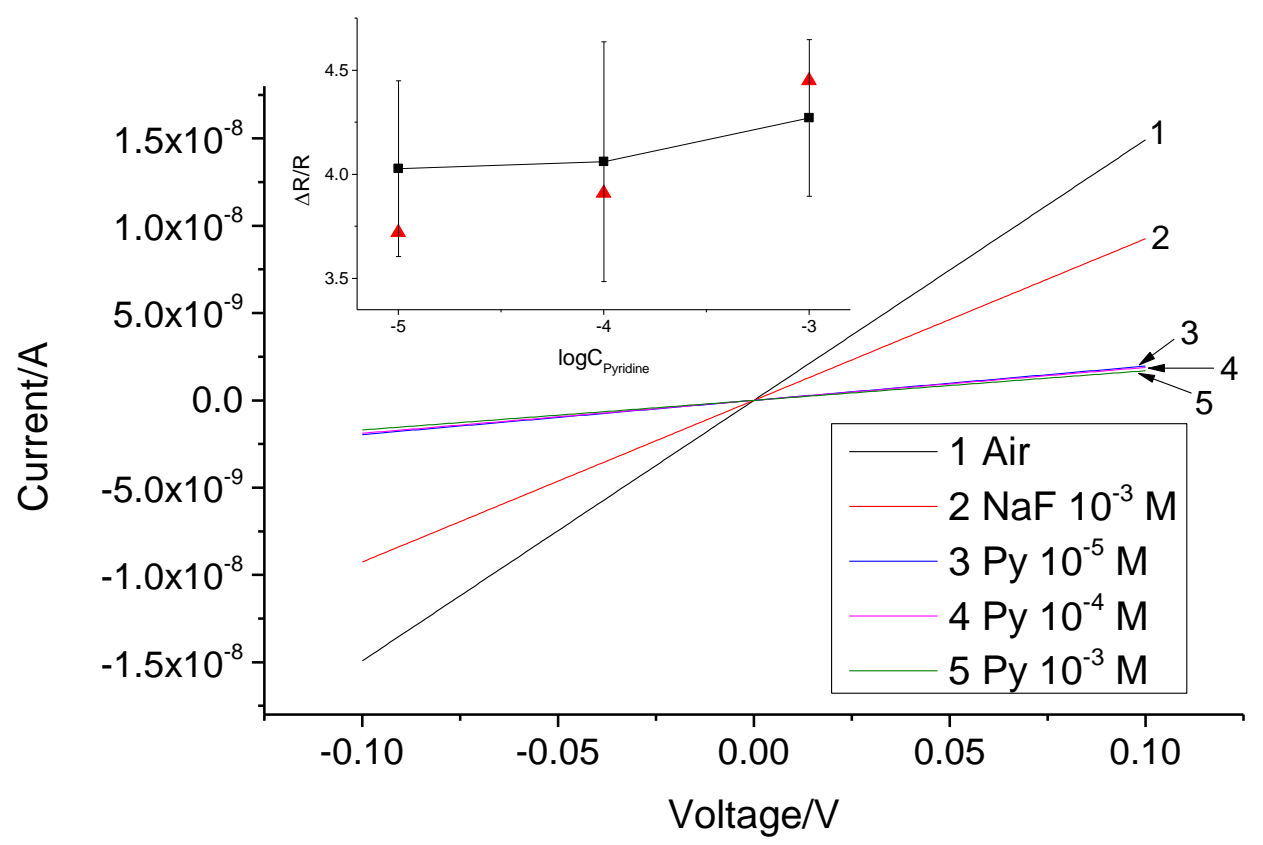

Fig. 7. Current-voltage dependences obtained for a chemiresistor chip with $600 \mathrm{~nm}$ distance between the contact electrodes and $5 \mu \mathrm{m}$ distances from the adjacent contact electrode pairs. The data refer to the electrodes in contact with the ambient air, with $1 \mathrm{mM} \mathrm{NaF}$, and with pyridine solutions. The inset shows the $\Delta R / R$ values vs. logarithm of the pyridine concentration (average data for the whole chip). Triangles in the inset refer to current-voltage dependences shown in the main figure.

\subsection{Dopamine sensitivity of Au NWs chemiresistors}

Dopamine and other neurotransmitters play a specific role in the human body [59]. The deviations from optimal concentration of dopamine in the body are associated with Parkinson's 
and Huntington's diseases, schizophrenia, memory and learning abilities, cardiovascular and behavior disorders [60-62]. Those who are developing dopamine sensors have to achieve two primary goals: detection limit below $10^{-7} \mathrm{M}$, and selectivity against ascorbic and uric acids - the main interferences in the dopamine sensing. These are challenging requirements, and this is why research and development work in the area of dopamine sensors continues. Achievements and trends in electrochemical sensing of dopamine have been recently reviewed [63]. A very promising approach one is the use of the generator-collector microwell electrode array [64]. The use of nanowire sensors for the dopamine quantification also appears promising [65-67].

We recently have performed a comparative study of potentiometric and voltammetric sensing modes for dopamine [68]. Here we explore the possibility to measure dopamine concentration using a gold NWs chemiresistor based on the DA adsorption. Since (i) dopamine has to be measured at low concentrations, and (ii) the results obtained here with halides and pyridine imply strong adsorption already from $10^{-5} \mathrm{M}$ solutions, for the measurements with aqueous dopamine solutions we have chosen a broad concentration range: from $10^{-8}$ to $10^{-2} \mathrm{M}$. Solutions contained phosphate buffer $\mathrm{pH} 7$ containing $0.05 \mathrm{M} \mathrm{Na}_{2} \mathrm{HPO}_{4}$ and $0.05 \mathrm{M} \mathrm{NaH}_{2} \mathrm{PO}_{4}(\mathrm{~PB})$ as a background electrolyte.

The I-V characterization was done for the devices with a distance of $800 \mathrm{~nm}$ between the electrodes in the contact electrode pairs. The results are shown in Fig. 8. Similar to other agents studied, the increase of the dopamine concentration causes the increase of the NWs resistance. Since PB was used as a background electrolyte, the chip resistance in contact of PB was used as $R_{\text {Ref }}$.

The relative change of the resistance $\Delta R / R$ varies from approx. 0.1 for $10^{-8} \mathrm{M}$ dopamine to approx. 0.7 for $10^{-5} \mathrm{M}$ dopamine, and saturates at this level. Thus, the relative change of the resistance is significantly lower than in the case of bromide and pyridine, but already at the level of $\Delta R / R \approx 0.7$ the effect gets saturated, suggesting a full coverage of the gold NWs surface. This apparent inconsistency may be due to two reasons. Firstly, the $R_{\text {Ref }}$ value for PB is about $10^{7} \Omega$ while for $10^{-3} \mathrm{M} \mathrm{NaF}$ it is about $10^{6} \Omega$, thus the same or even higher absolute changes of the resistance cause lower changes in $\Delta R / R$. Secondly, even if different species cover the gold NW surface to the same extent, the resulting changes of the electron scattering at the gold surface may be different and therefore may cause different changes of the NWs resistivity.

The saturation of the of $\Delta R / R$ value is observed already at $10^{-5} \mathrm{M}$ dopamine, while when in contact with halides and pyridine $\Delta R / R$ increases over the concentration range from $10^{-5}$ to $10^{-3}$ M. This suggests significantly stronger adsorption of dopamine, and, respectively, some selectivity of the resistometric signal in favor of dopamine. This selectivity, however, is not 
enough for the practical use because the excess of $\mathrm{Cl}^{-}$over dopamine in blood and urine is about 6 to 7 orders of magnitude. Therefore, further efforts are needed to make the gold NWs chemiresistor suitable for practical applications. In the absence of specific interactions, e.g., as provided by a bioreceptor, specificity and selectivity is often a problem in the case of chemiresistors $[13,39]$. The problem may be prospectively addressed as follows. One can try a classical approach: to purify the samples from the interferences, e.g. halides can be precipitated with $\mathrm{Ag}^{+}$. At physiological $\mathrm{pH}$, dopamine is protonated. This makes possible a more advanced approach: the chip must be equipped with an additional "gate" electrode, which can be placed either in the solution or structured on a chip next to the NWs contact electrodes and which will allow for shifting the potential of the NWs surface to the negative values by the electric filed effect. In this way, dopamine will be even more attracted to the NWs while halides and other anions will be repelled electrostatically.

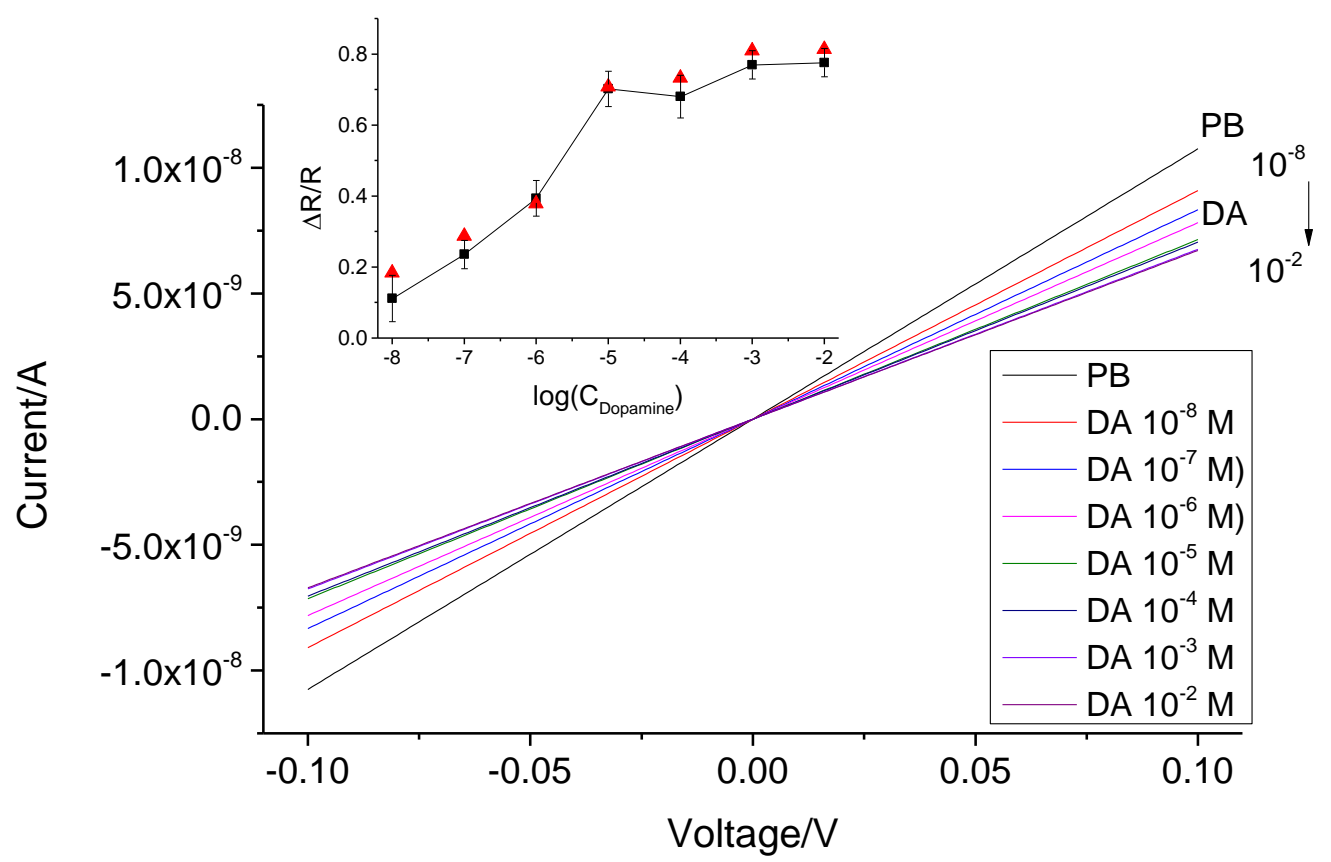

Fig 8. Current-voltage dependences obtained for a chemiresistor chip with a $800 \mathrm{~nm}$ distance between the contact electrodes and $5 \mu \mathrm{m}$ distances from the adjacent contact electrode pairs. The data refer to the electrodes in contact with PB and with PB + Dopamine solutions. The inset shows the $\Delta R / R$ values vs. logarithm of the dopamine concentration (average data for the whole chip). Triangles in the inset refer to current-voltage dependences shown in the main figure.

An overview of the analyte behavior for variations in the electrical resistance of the nanowires in solutions of the studied species is presented in Table 1 . 
Table 1. Variation in the electrical resistance $(\Delta R / R)$ of the Au nanowire devices after exposure to halides, pyridine and dopamine solutions. Value $\mathrm{n}$ refers to the number of the measurements used to obtain the average and the standard deviation of the $\Delta R / R$.

\begin{tabular}{ccccc}
\hline \multicolumn{5}{c}{$\Delta R / R$} \\
\hline $\begin{array}{c}\text { Concentration } \\
(\mathrm{M})\end{array}$ & $\mathrm{Cl}^{-}$ & $\mathrm{Br}^{-}$ & Pyridine & Dopamine \\
$10^{-8}$ & $\mathrm{n}=14$ & $\mathrm{n}=11$ & $\mathrm{n}=10$ & $\mathrm{n}=10$ \\
\hline $10^{-7}$ & & & $0.11 \pm 0.07$ \\
$10^{-6}$ & & & & $0.24 \pm 0.04$ \\
$10^{-5}$ & $0.35 \pm 0.24$ & $3.25 \pm 0.90$ & $4.03 \pm 0.42$ & $0.39 \pm 0.05$ \\
$10^{-4}$ & $0.50 \pm 0.35$ & $3.23 \pm 0.94$ & $4.06 \pm 0.57$ & $0.70 \pm 0.05$ \\
$10^{-3}$ & $0.80 \pm 0.40$ & $4.18 \pm 1.10$ & $4.27 \pm 0.38$ & $0.68 \pm 0.06$ \\
$10^{-2}$ & & & & $0.77 \pm 0.04$ \\
\hline
\end{tabular}

It appears useful to consider the obtained data also in the terms of conductance. The results are presented in Fig. 9. One can see that the NWs conductance is strongly dependent on the dopamine concentration up to $10^{-5} \mathrm{M}$ dopamine, and at higher concentrations the effect is saturated. Furthermore, within the concentration range from $10^{-8}$ to $10^{-5} \mathrm{M}$ the conductance is roughly linear dependent on the logarithm of the DA concentration (straight line 1 in Fig. 9). This appears very promising for a practical application of such devices as dopamine sensors. 


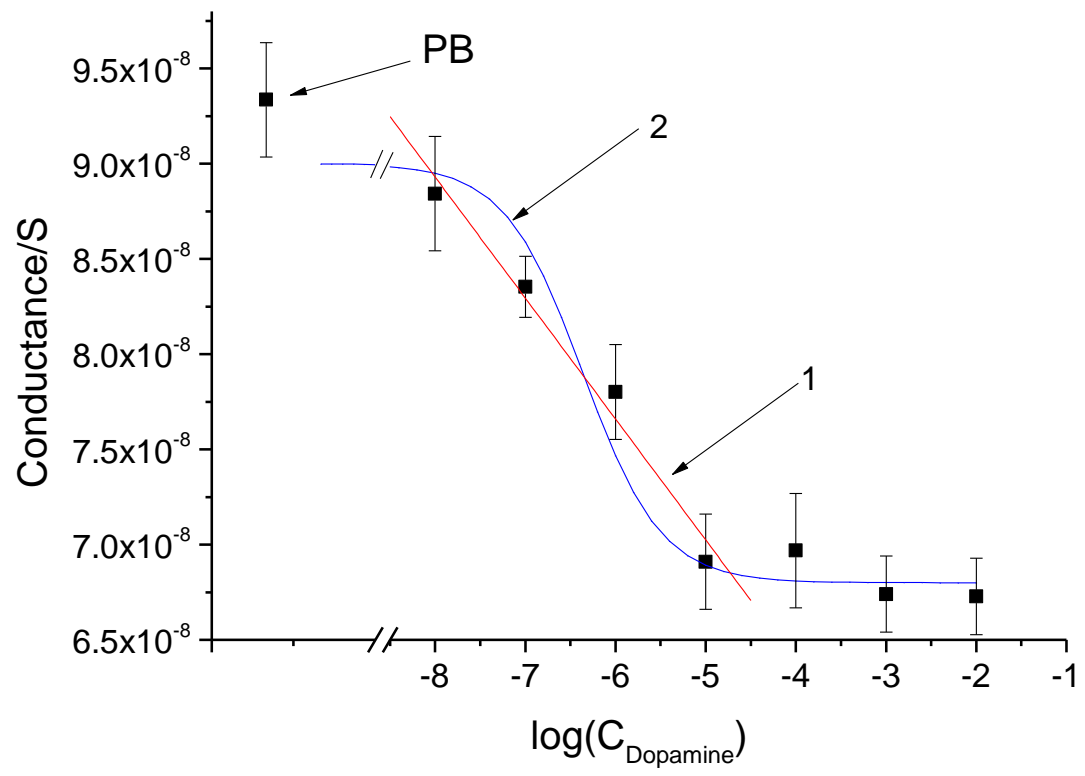

Fig. 9. Conductance of the NWs chips in contact with dopamine solutions with $\mathrm{PB}$ as a background electrolyte. Straight line 1 represents the linear regression of the data for $10^{-8}$ to $10^{-5}$ M dopamine. Sigmoidal line 2 is the result of fitting the data to Eqs. (3) and (4).

Conductance of nanowires is dependent on $\Theta$ : the coverage of the NWs surface by the adsorbed species. According to the Langmuir adsorption model, the dependence of $\Theta$ on logarithm of the species concentration forms a sigmoidal curve also containing a linear domain. Therefore, we tried to rationalize the dependence of the NWs conductance in contact with dopamine solutions using a simple model based on the following assumptions: (i) the experimentally measured conductance of the NWs array on a chip is determined by the coverage of the NWs surface with the adsorbate; (ii) the surface coverage obeys the Langmuir isotherm equation. These assumptions allow describing the conductance as follows:

$G=G_{P B}(1-\Theta)+G_{D A} \Theta$

$\Theta=\frac{K_{D A}{ }^{a d s} C_{D A}}{1+K_{D A}{ }^{a d s} C_{D A}}$

In Eq. (3) $G$ is the experimentally measured conductance, $G_{P B}$ is the conductance when the NWs are equilibrated with the PB solution, $G_{D A}$ is the conductance when the NWs are covered with dopamine, and $\Theta$ is the coverage of the NWs surface with dopamine. In Eq. (4) $K_{D A}{ }^{a d s}$ is the 
Langmuir adsorption constant for dopamine on gold, and $C_{D A}$ is the dopamine nominal concentration in solution.

Use of the nominal concentration values of dopamine implies that solution is not depleted in dopamine by sorption on the NWs surface. According to [69] the dopamine saturation coverage on gold surface equals $6.4 \cdot 10^{-10} \mathrm{~mol} \mathrm{\textrm {cm } ^ { 2 }}$. Given the chip/solution contact area in our case was $1 \cdot 10^{-6} \mathrm{~cm}^{2}$, and the volume of the solution drop was $20 \mu$, this means that even in the case of $10^{-8} \mathrm{M}$ dopamine solution the fraction of dopamine molecules adsorbed on gold surface did not exceed $0.3 \%$. Thus, the equilibrium concentration of dopamine in solutions was equal to the nominal concentration, and therefore the latter can be used as $C_{D A}$ in Eq. (4). The best fit of the experimental data (blue line in Fig. 8) was obtained with the following parameter values: $G_{P B}=$

$9.0 \cdot 10^{-8} \mathrm{~S}, G_{D A}=6.8 \cdot 10^{-8} \mathrm{~S}$, and $K_{D A}{ }^{a d s}=1.8 \cdot 10^{6} \mathrm{M}^{-1}$. Intuitively, the value $K_{D A}{ }^{a d s}=1.8 \cdot 10^{6}$ $\mathrm{M}^{-1}$, as well as the respective value of the free energy of adsorption of approximately $-36 \mathrm{~kJ}$ $\mathrm{mol}^{-1}$, appear fairly high. On the other hand, our estimate is not too far from $K_{D A}{ }^{a d s}=4.36 \cdot 10^{5}$ $\mathrm{M}^{-1}$ for the adsorption of dopamine on gold reported elsewhere [69].

\section{Conclusions}

Direct synthesis of ultrathin gold NWs on chips appears to be a promising approach for the preparation of chemiresistors due to better contact between the NWs and electrodes, and a higher stability of the NWs on chips if compared with the NWs deposition by the microfluidic technique.

Adsorption of chloride, bromide, pyridine, and dopamine on the gold NWs surface causes significant changes of the NWs resistance, and these changes may be used as the sensor signal for quantifying some of these species, in particular chloride and dopamine, in aqueous samples. The chip conductance may also be used as the sensor signal. Tentatively, we conclude that the linearity of the conductance response to dopamine vs. the logarithm of the dopamine concentration can be related to the Langmuir-type adsorption of dopamine on the gold NWs surface.

On the other hand, at least at the current stage, chemiresistors based on the ultrathin gold NWs deposited on chips are very fragile and difficult to provide reproducible results. Additionally they are not stable enough over time, with the life time of about two to three weeks. Further significant efforts are needed to address the aspect of selectivity and to make these sensors reliable, precise, and long-lasting.

\section{Acknowledgements}


Dr. G. Panaitov is gratefully acknowledged for helpful discussions. Ms. Hannah Freyer is gratefully acknowledged for the improving of the English of the paper. Financial support from the St.Petersburg State University (grant 12.38.235.2014) is gratefully acknowledged.

\section{References}

1. C. Zhu, G. Yang, H. Li, D. Du, Y. Lin, Electrochemical Sensors and Biosensors Based on Nanomaterials and Nanostructures, Anal. Chem. 87 (2015) 87 230-249 dx.doi.org/10.1021/ac5039863

2. K N Mikhelson, M A Peshkova, Ionophore-based chemical sensors: advances and prospects, Russ Chem Rev. 84 (2015) 555-578 dx.doi.org/10.1070/RCR4506

3. B.K. Duan, J. Zhang, P.W. Bohn, Conductance-Based Chemical Sensing in Metallic Nanowires and Metal-Semiconductor Nanostructures, Anal. Chem. 84 (2012) 2-8, dx.doi.org/10.1021/ac201240w.

4. B. Xu, H. He, N.J. Tao, Controlling the Conductance of Atomically Thin Metal Wires with Electrochemical Potential, J. Am. Chem. Soc. 124 (2002) 13568-13575, doi: $10.1021 / \mathrm{ja} 027810 \mathrm{q}$.

5. R.M. Penner, Chemical sensing with nanowires, Annu. Rev. Anal. Chem. 5 (2012) 461485 doi: 10.1146/annurev-anchem-062011-143007.

6. R.G. Tobin, Mechanisms of adsorbate-induced surface resistivity - experimental and theoretical developments, Surf. Sci. 502-503 (2002) 374-387, doi: 10.1016/S00396028(01)01978-1.

7. J. Lipkowski, L. Stolberg, Molecular adsorbtion at gold and silver electrodes, in: J. Lipkowski, P.N. Ross (Eds.), Adsorption of molecules at Metal electrodes, VCH, Weinheim, Cambridge, 1992 171-238.

8. K. Fuchs, H.H. Wills, The conductivity of thin metallic films according to the electron theory of metals, Proc. Cambridge Phyl. Soc. 34 (1938) 100-108.

9. E.H. Sondheimer The mean free path of electrons in metals, Advances in Physics, 1:1 (1952) 1-42, doi: 10.1080/00018735200101151

10. B.N.J. Persson, Surface resistivity and vibrational damping in adsorbed layers, Phys. Rev. B, 44 (1991) 3277-3296 doi: 10.1103/PhysRevB.44.3277.

11. B.N.J. Persson, Applications of surface resistivity to atomic scale friction, to the migration of "hot" adatoms, and to electrochemistry, J. Chem. Phys. 98 (1993) 16591672 doi: $10.1063 / 1.464282$. 
12. F.J. Ibanez, F.P. Zamborini, Chemiresistive Sensing with Chemically Modified Metal and Alloy Nanoparticles, Small 8 (2012) 2 174-202 doi: 10.1002/smll.201002232.

13. R.W. Murray, Nanoelectrochemistry: Metal Nanoparticles, Nanoelectrodes, and Nanopores, Chem. Rev. 108 (2008) 2688-2720 doi: 10.1021/cr068077e.

14. A. Zabet-Khosousi, A.-A. Dhirani, Charge Transport in Nanoparticle Assemblies, Chem. Rev. 108 (2008) 4072-4124 doi: 10.1021/cr0680134.

15. K. Saha, S.S. Agasti, C. Kim, X. Li, V.M. Rotello, Gold Nanoparticles in Chemical and Biological Sensing, Chem. Rev. 112 (2012) 2739-2779 dx.doi.org/10.1021/cr2001178.

16. J.S. Cooper, B. Raguse, E. Chow, L. Hubble, K.-H. Müller, L. Wieczorek, Gold Nanoparticle Chemiresistor Sensor Array that Differentiates between Hydrocarbon Fuels Dissolved in Artificial Seawater, Anal. Chem. 82 (2010) 3788-3795 doi: $10.1021 / \mathrm{ac} 1001788$.

17. L.J. Hubble, E. Chow, J.S. Cooper, M. Webster, K.-H. Müller, L. Wieczorek, B. Raguse, Gold nanoparticle chemiresistors operating in biological fluids, Lab. Chip. 12 (2012) 3040-3048 doi: 10.1039/c2lc40575j.

18. S. Kochmann, T. Hirsch, O.S. Wolfbeis, Graphenes in chemical sensors and biosensors, Trends in Analytical Chemistry 39 (2012) 87-113 doi: 10.1016/j.trac.2012.06.004.

19. J. Liu, Z. Liu, C.J. Barrow, W. Yang, Molecularly engineered graphene surfaces for sensing applications, Analyt. Chim. Acta 859 (2015) 1-19 doi: 10.1016/j.aca.2014.07.031.

20. M. Myers, J. Cooper, B. Pejcic, M. Baker, B. Raguse, L. Wieczorek, Functionalized graphene as an aqueous phase chemiresistor sensing material, Sens. Actuators B 155 (2011) 154-158 doi: 10.1016/j.snb.2010.11.040.

21. J.H. Shu, H.C. Wikle, B.A. Chin, Passive chemiresistor sensor based on iron (II) phthalocyanine thin films for monitoring of nitrogen dioxide, Sens. Actuators B 148 (2010) 498-503 doi: 10.1016/j.snb.2010.05.017.

22. C. Tlili, N.V. Myung, V. Shetty, A. Mulchandani, Label-free, chemiresistor immunosensor for stress biomarker cortisol in saliva, Biosensors and Bioelectronics 26 (2011) 4382- 4386 doi: 10.1016/j.bios.2011.04.045.

23. M.D. Shirsat, T. Sarkar, J. Kakoullis, N.V. Myung, B. Konnanath, A. Spanias, A. Mulchandani, Porphyrin-Functionalized Single-Walled Carbon Nanotube Chemiresistive Sensor Arrays for VOCs, J. Phys. Chem. C 116 (2012) 3845-3850 doi: $10.1021 /$ jp210582t. 
24. L.K. Randeniya, P.J. Martin, A. Bendavid, J. McDonnell, Ammonia sensing characteristics of carbon-nanotube yarns decorated with nanocrystalline gold, Carbon 49 (2011) 5265-5270 doi: 10.1016/j.carbon.2011.07.044.

25. X. Yang, L. Li, Y. Zhao, Ag/AgCl-decorated polypyrrole nanotubes and their sensory properties, Synth. Metals 160 (2010) 1822-1825 doi: 10.1016/j.synthmet.2010.06.018.

26. C. Tlili, L.N. Cella, N.V. Myung, V. Shetty, A. Mulchandani, Single-walled carbon nanotube chemoresistive label-free immunosensor for salivary stress biomarkers, Analyst 135 (2010) 2637-2642 doi: 10.1039/C0AN00332H.

27. U. Lange, V.M. Mirsky, Chemiresistors based on conducting polymers: A review on measurement techniques, Analyt. Chim. Acta 687 (2011) 105-113 doi: 10.1016/j.aca.2010.11.030.

28. S. Srinives, T. Sarkar, R. Hernandez, A. Mulchandani, A miniature chemiresistor sensor for carbon dioxide, Analyt. Chim. Acta 874 (2015) 54-58 doi: 10.1016/j.aca.2015.03.020.

29. H.-M. Jeong, H.-J. Kim, P. Rai, J.-W. Yoon, J.-H. Lee, Cr-doped $\mathrm{Co}_{3} \mathrm{O}_{4}$ nanorods as chemiresistor for ultraselective monitoring of methyl benzene, Sens. Actuators B 201 (2014) 482-489 http://dx.doi.org/10.1016/j.snb.2014.05.038.

30. S. Sahin, S. Altun, A. Altindal, Z. Odabas, Synthesis of novel azo-bridged phthalocyanines and their toluene vapour sensing properties, Sens. Actuators B 206 (2015) 601-608 doi: 10.1016/j.snb.2014.09.110.

31. C. Tlili, S. Badhulika, T.-T. Tran, I. Lee, A. Mulchandani, Affinity chemiresistor sensor for sugars, Talanta 128 (2014) 473-479 doi: 10.1016/j.talanta.2014.05.055.

32. J.S. Cooper, M. Myers, E. Chow, L.J. Hubble, J.M. Cairney, B. Pejcic, K.-H. Müller, L. Wieczorek, B. Raguse, Performance of graphene, carbon nanotube, and gold nanoparticle chemiresistor sensors for the detection of petroleum hydrocarbons in water, J Nanopart. Res. 16 (2014) 2173 doi: 10.1007/s11051-013-2173-5.

33. J. Kong, N. R. Franklin, C. Zhou, M.G. Chapline, S. Peng, K. Cho, H. Dai, Nanotube Molecular Wires as Chemical Sensors, Science,287 (2000) 622-625, doi: $10.1126 /$ science.287.5453.622.

34. E. C. Walter, R. M. Penner, H. Liu, K.H. Ng, M. P. Zach, F. Favier, Sensors from electrodeposited metal nanowires, Surf. Interface Anal. 34 (2002) 409-412. doi: $10.1002 /$ sia.1328

35. E. Stern, J. F. Klemic, D. A. Routenberg, P. N. Wyrembak, D. B. Turner-Evans, A. D. Hamilton, D. A. LaVan, T. M. Fahmy and M. A. Reed, Label-free immunodetection with 
CMOS-compatible semiconducting nanowires, Nature 445 (2007) 519-522 doi: 10.1038/nature05498.

36. B. Wang, L. F. Zhu, Y. H. Yang, N. S. Xu and G. W. Yang, Fabrication of a $\mathrm{SnO}_{2}$ Nanowire Gas Sensor and Sensor Performance for Hydrogen. J. Phys. Chem. C 112 (2008) 6643-6647 doi: 10.1021/jp8003147.

37. Y. Engel, R. Elnathan, A. Pevzner, G. Davidi, E. Flexer, F. Patolsky, Supersensitive Detection of Explosives by Silicon Nanowire Arrays, Angew. Chem., Int. Ed. 49 (2010) 6830-6835 doi: 10.1002/anie.201000847.

38. R. Yu, C. Pan and Z. L. Wang, High performance of $\mathrm{ZnO}$ nanowire protein sensors enhanced by the piezotronic effect, Energy Environ. Sci. 6 (2013) 494-499 doi: 10.1039/c2ee23718k.

39. A. Kisner, M. Heggen, D. Mayer, U. Simon, A. Offenhäusser, Y. Mourzina, Probing the effect of surface chemistry on the electrical properties of ultrathin gold nanowire sensors, Nanoscale 6 (2014) 5146-5155 doi: 10.1039/C3NR05927H.

40. H.-Y. Lin, H.-A. Chen, H.-N. Lin, Fabrication of a Single Metal Nanowire Connected with Dissimilar Metal Electrodes and Its Application to Chemical Sensing, Anal. Chem. 80 (2008) 1937-1941 doi: 10.1021/ac701911j.

41. Z. Liu, P.C. Searson, Single Nanoporous Gold Nanowire Sensors, J. Phys. Chem. B 110 (2006) 4318-4322 doi: 10.1021/jp056940t.

42. F. Yang, K.C. Donavan, S.-C. Kung, R.M. Penner, The Surface Scattering-Based Detection of Hydrogen in Air Using a Platinum Nanowire, Nano Lett. 12 (2012) 2924-2930 dx.doi.org/10.1021/n1300602m

43. X. Li, Y. Liu, J.C. Hemminger, R.M. Penner, Catalytically Activated Palladium and Platinum Nanowires for Accelerated Hydrogen Gas Detection, ACS NANO 9 (2015) 3215-3225 doi: 10.1021/acsnano.5b00302

44. Mulchandani, N.V. Myung, Conducting polymer nanowires-based label-free biosensors, Current Opinion in Biotechnology 22 (2011) 502-508

Doi: 10.1016/j.copbio.2011.05.508.

45. Y. Zhou, H. Zhang, H. Xie, B. Chen, L. Zhang, X. Zheng, P. Jia, A novel sensor based on LaPO4 nanowires modified electrode for sensitive simultaneous determination of dopamine and uric acid, Electrochim. Acta 75 (2012) 360-365 doi: 10.1016/j.electacta.2012.05.023.

46. A. Roy, T. Pandey, N. Ravishankar, A.K. Singh, Semiconductor-like Sensitivity in Metallic Ultrathin Gold Nanowire-Based Sensors, J. Phys. Chem. C 118 (2014) 18676-18682 dx.doi.org/10.1021/jp5042052. 
47. H.O. Finklea, Electrochemistry of organized monolayers of thiols and related molecules on electrodes, in A.J. Bard, I. Rubinstein (Eds.) Electroanalytical Chemistry. A series of advances, V. 19, Marcel Dekker, Inc. 1996 110-337.

48. J.C. Love, L.A. Estroff, J.K. Kriebel, R.G. Nuzzo, G.M. Whitesides, Self-Assembled Monolayers of Thiolates on Metals as a Form of Nanotechnology, Chem. Rev. 105 (2005) 1103-1169 doi: 10.1021/cr0300789.

49. U. Chandni, P. Kundu, A.K.Singh, N. Ravishankar, A. Ghosh, Insulating State and Breakdown of Fermi Liquid Description in Molecular-Scale Single-Crystalline Wires of Gold, ACS Nano (2011) 8398-8403 doi: 10.1021/nn2031935.

50. A. Halder, N. Ravishankar, Ultrafine Single-Crystalline Gold Nanowire Arrays by Oriented Attachment, Adv. Mater. 19 (2007) 1854-1858, doi: 10.1002/adma.200602325.

51. J. F. Banfield, S. A. Welch, H. Zhang, T. T. Ebert, R. L. Penn, Aggregation-Based Crystal Growth and Microstructure Development in Natural Iron Oxyhydroxide Biomineralization Products, Science 289 (2000) 751-754 doi: 10.1126/science.289.5480.751.

52. S. Link, M. B. Mohamed, M. A. El-Sayed, Simulation of the Optical Absorption Spectra of Gold Nanorods as a Function of Their Aspect Ratio and the Effect of the Medium Dielectric Constant, J Phys Chem B 103 (1999) 3073-3077 doi: 10.1021/jp990183f.

53. S. Pud, A. Kisner, M. Heggen, D. Belaineh, R. Temirov, U. Simon, A. Offenhöusser, Y. Mourzina, S. Vitusevich, Features of Transport in Ultrathin Gold Nanowire Structures, Small 9 (2012) 846-852 doi: 10.1002/smll.201202197

54. J. Clavilier, N.V. Huong, Étuide de la structure de la couche double sur les électrodes d'or, Electroanal.Chem. Interfacial Electrochem. 41 (1973) 193-199 doi: 10.1016/S00220728(73)80437-1.

55. R.I. Tucceri, D. Posadas, A surface conductance study of the anion adsorption on gold. J Electroanal Chem 191 (1981) 387-399 doi: 10.1016/S0022-0728(85)80031-0.

56. L. Stolberg, J. Richer, J. Lipkowski, D.E. Irish, Adsorption of pyridine at the polycrystalline gold-solution interface, J. Electroanal. Chem. 207 (1986) 213-234 doi: 10.1016/0022-0728(86)87073-5.

57. P. Zelenay, L. M. Rice-Jackson, A. Wieckowski, Adsorption of pyridine on polycrystalline gold electrode studied by radioactive-labeling method, Langmuir 6 (1990) 974-979 doi: 10.1021/1a00095a015.

58. K. Tonigold, A. Groß, Adsorption of small aromatic molecules on the (111) surfaces of noble metals: a DFT study with semi-empirical corrections for dispersion effects, J. Chem. Phys. 132, 224701-01 - 224701-10 (2010) doi: 10.1063/1.3439691. 
59. J.R. Cooper, F.E. Bloom, R.H. Roth, The Biochemical Basis of Neuropharmacology, Oxford University Press, Oxford, UK, 1982.

60. Normal Hormone Reference Ranges. Greenspans Basic \& Clinical Endocrinology, 9th ed., McGraw-Hill, New York, 2011.

61. V. Hefco, K. Yamada, A. Hefco, L. Hrticu, A. Tiron, T. Nabeshima, Role of the mesotelencephalic dopamine system in learning and memory processes in the rat, Eur. J. Pharmacol. 475 (2003) 55-60 doi: 10.1016/S0014-2999(03)02115-0.

62. J.W. Dalley, J.P. Roiser, Dopamine, serotonin and impulsivity, Neuroscience 215 (2012) 42-58 doi: 10.1016/j.neuroscience.2012.03.065.

63. K Jackowska, P. Krysinski, New trends in the electrochemical sensing of dopamine, Anal Bioanal Chem 405 (2013) 3753-3771 doi: 10.1007/s00216-012-6578-2.

64. A. Oleinick, F. Zhu, J. Yan, B. Mao, I. Svir, C. Amatore, Theoretical Investigation of Generator-Collector Microwell Arrays for Improving Electroanalytical Selectivity: Application to Selective Dopamine Detection in the Presence of Ascorbic Acid, ChemPhysChem 14 (2013) 1887 - 1898, doi: 10.1002/cphc.201300134.

65. Y. Lu, M. Yang, F. Qu, G. Shen, R. Yu, Enzyme functionalized gold nanowires for the fabrication of biosensors. Bioelectrochemistry 71 (2007) 211-216 doi: 10.1016/j.bioelechem.2007.05.003

66. U. Yogeswaran, S.-M. Chen, A review on the electrochemical sensors and biosensors composed of nanowires as sensing materials, Sensors 8 (2008) 290-313 doi: $10.3390 / \mathrm{s} 8010290$

67. P. Tagi, D. Postetter, D.L. Saragnese, C.L. Randall, M.A. Mirski, D.H. Gracias, Patternable nanowire sensors for electrochemical recording of dopamine. Anal Chem, 81 (2009) 9979-9984 doi: 10.1021/ac901744s

68. I.S. Muratova, L.A. Kartsova, K.N. Mikhelson, Voltammetric vs. Potentiometric Sensing of Dopamine: Advantages and Disadvantages, Novel Cell Designs, Fundamental Limitations and Promising Options, Sens. Actuators B Chemical, 207 (2015) 900-906 doi: 10.1016/j.snb.2014.07.034

69. M.K. Zachek, A Hermans, R.M. Wightman, G.S. McCarty, Electrochemical Dopamine Detection: Comparing Gold and Carbon Fiber Microelectrodes using Background Subtracted Fast Scan Cyclic Voltammetry, J. Electroanal. Chem. 614 (2008) 113-120, doi: 10.1016/j.jelechem.2007.11.007. 